\title{
UTILIZATION OF SOLID LIPID NANOPARTICLES LOADED ANTICANCER AGENTS AS DRUG DELIVERY SYSTEMS FOR CONTROLLED RELEASE
}

\author{
Ibtihag Yahya \\ Research Assistant \\ Department of Biomeical Engineering, \\ Sudan University of Science and Technology, \\ PO Box 407, Khartoum, Sudan \\ Lina Ahmed \\ Research Assistant \\ Department of Biomedical Engineering, \\ Sudan University of Science and Technology, \\ PO Box 407, Khartoum, Sudan \\ Akram Omara \\ Assistant Professor \\ Department of Biomedical Engineering, \\ Sudan University of Science and Technology, \\ PO Box 407, Khartoum, Sudan
}

\begin{abstract}
Cancer" is the most terrifying disease, just hearing the word " $\mathrm{C}$ " is a horror for every patient. Notably, the conventional doses form of taking the anticancer drugs are having ruthless side effects and high toxicity on the patient's body. The design of nanoparticles while maintaining the sink condition in the laboratory release trials is one of the biggest challenges and difficulties in design, especially those low-solubility drugs that are used as anticancer agent carriers. If the doctor is aware of the pharmacokinetics of chemotherapy, it will facilitate and help in determining the amount of dosage required in order to obtain a high therapeutic accuracy and reduce toxicity and affect healthy cells. For this purpose, this paper aims to simulate the pharmacokinetic of different types of chemotherapeutic agents to study the kinetics based on solid lipid drug delivery systems nanoparticles (SLN) by examining drug release from different types of devices such as matrix system and reservoir devices controlled by the diffusion mechanism using preposed and estimated values extracted from literature studies which will help to manufacture nanoparticles that meet specific requirements. In order to determine which device type is optimal and best to use as a drug delivery system to cancerous cells and then examin the effect of particle size of this type, ranging from 10 to
\end{abstract}

\author{
Razan Atif \\ Research Assistant \\ Department of Biomedical Engineering, \\ Sudan University of Science and Technology, \\ PO Box 407, Khartoum, Sudan \\ Tahleel Salah Eldeen \\ Research Assistant \\ Department of Biomedical Engineering, \\ Sudan University of Science and Technology, \\ PO Box 407, Khartoum, Sudan \\ Megdi Eltayeb \\ Assistant Professor \\ Department of Biomedical Engineering, \\ Sudan University of Science and Technology, \\ PO Box 407, Khartoum, Sudan
}

$100 \mathrm{~nm}$ on the anticancer drug relese and decide the best size that give the requierd dose of each chemotherapy drugs that were used in this study, we simulated the release behavior of nanoparticles with nano-sphare geometry using the MATLAB software. As majour finding of this study, the solid lipid based nanoparticles for drug delivery with matrix solution system type shows prolonged drug release which means that this type of systems have high loading capacity of the various chemotheraputic active compounds and can be use sucssfuly as anticancer agent drug delivery.

Keywords-Nanoparticles, Cancer treatment, Drug delivery, Solid lipid, Anticancer drug

\section{INTRODUCTION}

Cancer is the disease that occurs because of the proliferation of cells in an abnormal and uncontrolled in certain places of the body, which produces different types of cancer, according to the place where this imbalance Werner et al.(2016). As an illustration, the anomalies and proliferation are induced by the genetically changes that control both the regulatory mechanisms and cell signaling Friberg et al.(2005). The 


\section{International Journal of Engineering Applied Sciences and Technology, 2020 \\ Vol. 4, Issue 10, ISSN No. 2455-2143, Pages 277-286 \\ Published Online February 2020 in IJEAST (http://www.ijeast.com)}

fact is that, our bodies are made of different cells and among these cells are the cancerous cells, but not always able to be active. Which means It is not our end are the cancer disease and the hospital. The delivery of the drug to the cancer cells in particular is important to improve the effect of drugs where the release of the drug directly to the cell disease only, without affecting the healthy cells, which contributes significantly to reduce the toxic side effects and increase the efficiency of the drug in the target location. In the light of taken the drug by traditional methods and a schedule for administering the drug which may be changed in the treatment trip based on the needs to repeat the dose or changed if you see more than one doctor Friberg et al.(2005; Jain(2005), which may significantly affect the outcome of the treatment as a result of the increased dose as these types of anti-cancer often have a narrow therapeutic window. Hence, the urgent need to develop drug delivery systems to control drug release based on nanoparticles, additionally using of new techniques that play an important role in effective treatment and also represents a fundamental goal of cancer treatment Bhatia(2016; da Silva Luz et al.(2016). One of the major challenges that scientists have sought over the years to overcome and break their restrictions is the response of the organism to drugs, which is one of the types of general responses to the various stressors and environmental impacts in a constantly changing environment Vizirianakis(2014). Thus, for decades the attention and direction was prominent for pharmaceutical research is to modify drug delivery systems and to seek the development of new dosage forms to overcome drug inefficacy and poisoning that lead to the failure of pharmacological treatment through the development of nanoparticle delivery systems as it contributes to providing the required therapeutic amount of medication to the appropriate location In the body to release it immediately and then maintain its desired concentration Negut et al.(2017; Thassu Deepak et al.(2007). In the first place the main objective of the study is to attracted the attention of interested researchers in this wonderful branch of nanotechnology which known as drug delivery system by examining drug release from different types of nanoparticles based-solid lipid as drug delivery system devices such as matrix system and reservoir devices controlled by the diffusion mechanism and then determin the release profiles for the best device type that is optimal to use as a drug delivery system to cancer cells.

\section{THEORY}

\section{A. Nanotechnology-based drug delivery systems}

Innovation and developments of the new technologies are a result of the urgent need to find new and effective methods of detecting and treating various diseases with less effort, cost and in the first place in short time, where the time factor is a big challenge to various diseases for the reason of, when they are detected in early time and early stage, the treatment will be more easily and efficiently and this is the major lacking in traditional methods Gharpure et al.(2015; Jabir et al.(2012). In the light of these needs in recent years, nanotechnology has gained the attention of researchers, where this technology points out as, the science that allows the study of material treated on the molecular scale and atomic material that ranges from less than 100 nanometers Yousaf et al.(2008). These technologies also allow manipulation, control, study and manufacture of devices with different structures in the range of nanometers Singh et al.(2009). As a key point, nanotechnology can be classified into several categories, which include their different uses due to their nanoscale size, which is not only used in the biomedical field, but also in delivering the drug to the target location Sahoo et al.(2003; Stylios et al.(2005). In fact, nanotechnology researches expanding and focusing especially in the areas of use in the delivery of drugs and genes, where this aspect has become increasingly important in the medical field as the drugs are characterized by the speceification and effectiveness where the spatial and temporal control of the drug. In addition to, prolong the duration of the release of the drug Muhamad12 et al.(2014; Zhang et al.(2013).

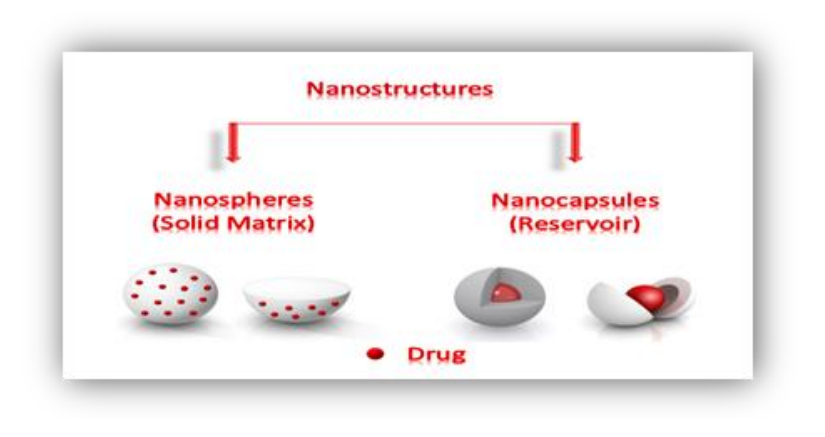

Figure 1: Scheme of Nanostructures (A) Nanospheres (matrix system) and (B) Nanocapsules (reservoir system).

In general, nanoparticles, which have recently emerged as an effective carrier technique in the delivery of drugs, can be defined as nanstructures with a scale less than 10 to 


\section{International Journal of Engineering Applied Sciences and Technology, 2020 \\ Vol. 4, Issue 10, ISSN No. 2455-2143, Pages 277-286 \\ Published Online February 2020 in IJEAST (http://www.ijeast.com)}

1,000 micrometers. The most widely used nanoparticles include polymers, liposomes, quantum dots, proteins, micelles, dendrimers and nanotube in which a drug is either encapsulated or conjugated to internal domains of the carrier Singh et al.(2009). Nanoparticles are a collective term called for both nanospheres (solid matrix) and nanocapsules (reservoir/core-shell), which are the two types commonly used depending on the nanoparticles preparation processes as sown in (

Figure 1).

\section{1) Solid lipid nanoparticles as drug delivery systems}

Fatty nanoparticles are one of the main systems widely used to deliver efficient ingredients because of their ability to protect them from unfavorable environmental conditions which will led to increases storage levels and releases active components at a constant rate, in addition improving bioavailability within the body Eltayeb et al.(2013). The lipid nanoparticles have two of the most commonly used particles type in used as drug delivery system based-solid lipid nanoparticles (SLN) which have many applications as illustrated in (Figure 2) and nanostructured lipid carrier (NIC) where the SLN consist of solid lipid rather than liquid lipid while the NLC consist of both types of lipid Naseri et al.(2015).

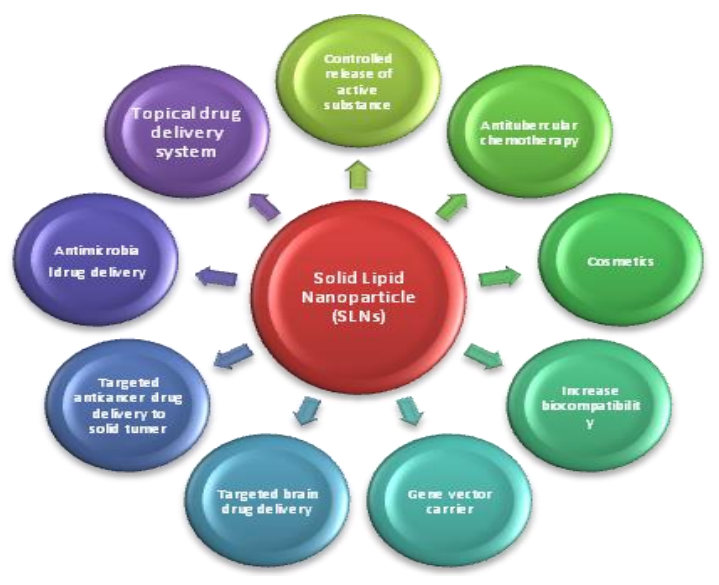

Figure 2: Applications of SLNs representation.

Because SLN is less toxic than polymeric nanoparticles, it is useful as a drug bearer to treat tumors because of their biological and biodegradable nature. In addition, they are able to prolong drug release after taking the dose. This means that the loading and incorporation of anti-cancer drugs into SLN to target tumors will be more effective and less toxic, and will release the appropriate dose Ruckmani et al.(2006; Shenoy et al.(2005).
III. METHOD

When talking about controlled drug delivery systems, it is important to describe the mechanisms that controlled and governed the drug release process. It is worth mentioning that a number of physical and chemical phenomena actually affect the release rates such as e.g., drug dissolution, a combination of water diffusion, drug diffusion, polymer/ lipid dissolution, polymer/ lipid swelling, and/or polymer/ lipid degradation Torchilin(2011). In this study, we focused on the diffusion process as it is one of the most extensive mechanisms that control the release of drugs from delivery systems. With attention to the mathematical approaches of diffusion mechanisms for drug release this study was conducted in order to examine the drug release kinetics based on solid lipid drug delivery systems nanoparticles (SLN) by examining drug release from different types of devices such as matrix system and reservoir devices controlled by the diffusion mechanism as shown in (Figure 3).

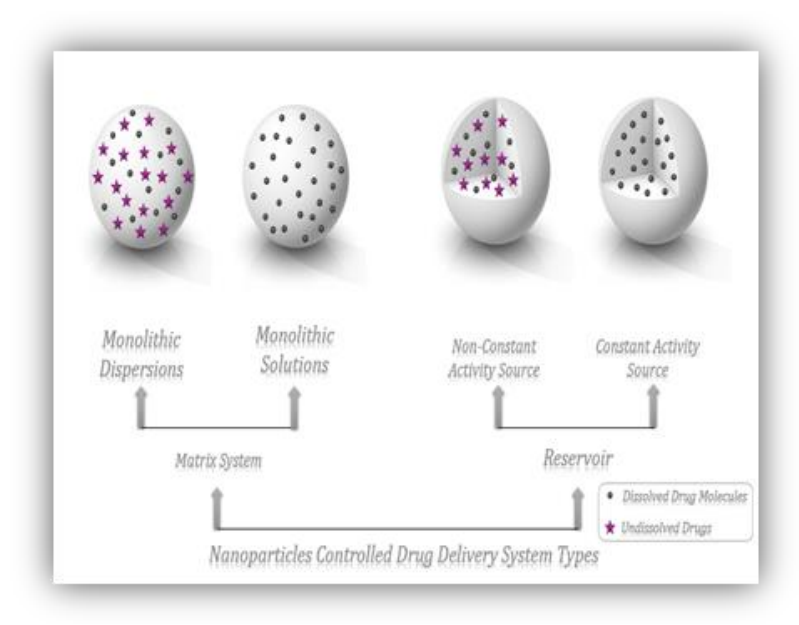

Figure 3: Schematic presentation of classification of the diffusioncontrolled drug delivery systems types.

\section{A. Monolithic Devices (Matrix-Based Solid Lipid Drug Delivery Systems)}

These systems are characterized by drug molecules being homogeneous, which means that the drug is dispersed or dissolved though out the matrix that controlling the release Heller(1987). It is important to know both the ratio or the concentration of the initial drug loaded in the device and the solubility of the drug which facilitate the differentiation between both monolithic solutions and monolithic dispersions and consider by which mechanism the drug is release. The matrix-based system can be classified based 


\section{International Journal of Engineering Applied Sciences and Technology, 2020 \\ Vol. 4, Issue 10, ISSN No. 2455-2143, Pages 277-286 \\ Published Online February 2020 in IJEAST (http://www.ijeast.com)}

on drug solubility and initial drug concentration ratio, as follow:

\subsubsection{Monolithic Solutions}

In the monolithic solutions matrix, the drug is released by diffusion out of a lipid matrix and the release rate when the initial drug concentration above solubility limit in matrix. Fick's laws of diffusion can be used in order to quantify diffusional behaviour through this devices type J. Siepmann \& Siepmann(2012):

$$
\frac{M_{t}}{M_{s \infty}}=1-\frac{6}{\pi^{2}} \sum_{n=1}^{\infty} \frac{\exp \left[-\mathrm{Dn}^{2} \pi^{2} t / \mathrm{R}^{2}\right]}{n^{2}}
$$

Where $\mathrm{R}$ represents the radius of the sphere.

\section{1) Monolithic Dispersions}

A single dispersion model where the drug is released by diffusion and controls the release rate by the solubility limitation of the homogeneous drug in the matrix Fan et al.(1989). They also have an initial concentration of drugs that significantly exceeds their solubility. Specifically, in this system part of the drud is dissolved in the matrix while the remainder is dispersed as non-dissolved (crystalline and / or amorphous) J. Siepmann, Siegel, et al.(2012). On the other side, the dispersion of the dissolved drug only can be rapidly replaced by the dissolution of the solid drug. The following equation can be used to decribed the release rate of this systeme F. Siepmann et al.(2006):

$$
\frac{M_{L}}{M_{m}}=4 \pi R^{2} \sqrt{\left(2 C_{s}-C_{s}\right) C_{s} D t}+\frac{4 C_{n} D t}{9 R}\left(\frac{C}{2 C-C_{m}}-3\right)
$$

where and represent the absolute cumulative amounts of drug released, $t$ is the time, $\mathrm{D}$ is the drug diffusion coefficient, $\mathrm{R}$ is the spherical device radius, are the initial drug concentration and is the drug solubility within the system.

\section{B. Reservoir Devices (Reservoir-Based Solid Lipid Drug Delivery Systems)}

The reservoirs system which called core-shell-structure delivery systems which represent one of the most common drug delivery systems in addition to the matrix systems. First thing to remember, these systems are controlled by the properties of the drug-encapsulated substance, which represent the essence of this drug as its composition, molecular weight and thickness, as well as the chemical and physical properties of the drug, such as the size of the drug molecules, solubility, and molecular weight Langer(1990). These systems are usually taken advantage of for one of the following applications Freiberg et al.(2004):

- In cases of targeted areas and difficult access through the systemic administration.

- Doses that require a long-term cycle and are highly toxic as cancer treatments.

- Medications that require medium or long term administration and are localized to any particular area of the body.

- Drug depot for long-term systemic management. The reservoir-based system can be classified based on drug solubility and initial drug concentration ratio, as follow:

\section{1) Reservoir System with Non-constant Activity Source}

In the case of reservoirs with non-constant source of activity, the drug encapsulated within core structure which is completely separated from the controlled release rate substance which forms the particle shell which surrounding the drug store and forms a barrier membrane Yang et al.(2012). In other words and as an illustration, the drug solubility is greater than the initial drug concentration. In other words, the molecules of the drug that are administered through the membrane are not replaced, so the concentration of the drug on the surface of the internal membrane gradually decreases over time Langer(1990). The drug diffusion through reservoir device with a "nonconstant activity source" to controlling the release rate via membrane can illustrated by the equation J. Siepmann \& Siepmann(2012):

$\frac{M_{\mathrm{t}}}{M_{\mathrm{so}}}=1-\exp \left(-\frac{3 R_{0} D K t}{R_{I}^{2} R_{0}-R_{i}^{3}}\right)$

where and represent the cumulative drug released at time $\mathrm{t}$ and infinity, respectively, $\mathrm{D}$ is the diffusion coefficient of the drug within the membrane, $\mathrm{K}$ is the partition coefficient of the drug between the membrane and the reservoir and and are the inner and outer radius of the device.

\section{2) Reservoir System with Constant Activity Source}

In the case of reservoirs with constant source of activity, the drug concentration become greater than drug solubility. Consequently, this system have limited solubility where only part of the drug is dissolved and the drug molecules that were released is fastly replaced by dissolution of the excess and remaining of non-dissolved drug in the matrix Yang et al.(2012). Thus, Fick's law of diffusion equation 


\section{International Journal of Engineering Applied Sciences and Technology, 2020 \\ Vol. 4, Issue 10, ISSN No. 2455-2143, Pages 277-286 \\ Published Online February 2020 in IJEAST (http://www.ijeast.com)}

can be used to descripe the release rate from spherical geometry:

$$
M_{t}=\frac{4 \pi D K c_{p} R_{0} R_{i}}{R_{e}-R_{i}} \times t
$$

Where is the solubility of the drug in the core.

\section{RESUlT AND DisSECTION}

In this section the MATLAB simulation results of the diffusional mathematical expressions of the drug release profiles and kinetics from SLN system types were represented and described. Markedly, solid lipid nanoparticles drug delivery systems with diffusion controlled delivery devices release mechanism can follow many types of devices (i.e. Matrix Devices which can be monolithic solutions or monolithic dispersion or Reservoir controlled devices with constant or with non-constant activity source etc). To point out, matrix release rate can control by choice of matrix type: (glassy matrix: D 10-10$10-12 \mathrm{~cm}^{2} / \mathrm{s}$ or rubbery matrix: $\left.\mathrm{D} \sim 10-6-10-7 \mathrm{~cm}^{2} / \mathrm{s}\right)$. In the monolithic matrix the drug is released by diffusion out of a lipid matrix and the release rate depends on initial drug concentration. By the same token, if the drug initial concentration $\mathrm{Ci}$ above solubility $\mathrm{Cs}$ limit in matrix the drug dissolution in polymer matrix limits release rate (Monolithic Solution) in inverse side if the initial drug concentration is below solubility limit in matrix the diffusion through matrix limits the release rate (Monolithic Dispersions). Similarly, matrix with monolithic solutions are homogeneous Nano-spheres solutions consisting of a complete spherical matrix characterized by the homogeneity of the drug, which can be immediately dissolved and distributed to the entire spherical matrix. In the case of this matrix system, we set the limit of drug initial concentration $\mathrm{Ci}=0.08 \mathrm{~g} / \mathrm{cm}^{2}$, drug solubility $\mathrm{Cs}=$ $0.06 \mathrm{~g} / \mathrm{cm}^{2}$ and varying the radius as $0.3,0.75$ and $1.20 \mathrm{~nm}$ in order to studying the release type compared with the reservoir type. From (Figure 4, Figure 5, Figure 6 and Figure 7) can clearly see that the form/type of release followed the first order or exponential release which means that the release kinetics are not zero order. By the same token, as shown in (Figure 4, Figure 5 and Figure 6) the release rate from matrix with monolithic dispersion is very low compare to the monolithic solution systems and the initial drug concentration $\mathrm{Ci}=0.06 \mathrm{~g} / \mathrm{cm}^{2}$ compared with the drug solubility $\mathrm{Cs}=0.08 \mathrm{~g} / \mathrm{cm}^{2}$ is low. The release rate has affected by radius of device, as the value of radius decrease, the release rate increase and follow a constant behavior.

From (Figure 4, Figure 5 and Figure 6), the ratio of the drug released over time from reservoir system is low compare to the matrix one. since this system is greatly affected by spherical particle device inner and outer radius, i.e., when the core-shell structure ratio was $2: 1$ and $3: 1$ for the delivery device formulations $F 1, F 2$ and $F 3$, respectively it is noticeable to observe that when the core: shell ratio is higher, the larger release rate, which mean that the larger the size of the core-structure as in F2 was twice greater than the shell, the greater the amount of drug loaded in the device. In this case of the reservoir device is characterized by a constant activity source that the drug release kinetics follow the zero-order release and the drug is released at a constant rate i.e. the concentration gradient of the drug within the membrane is constant. Moreover, because the drug is dispersed in the excretions, which is the basis of the particle, when the shell has a small thickness or the core: shell ratio is small, it facilitates water penetration of the system, which causes the molecules to dissolve quickly, so the dissolution of the drug compared to the diffusion of the drug is fast, resulting in the release of small amounts in this case for the Doxorubicin chemotherapeutic agent over 21 days. While the chemotherapy agent drugs need sustained release over days (continuous infusions) by diffusion while this type of release characterized by the low level of the drug by diffusion over time, which are considered as big challenge of this type of treatment Wyss Institute for Biologically Inspired Engineering at Harvard(2014). We found that, the solid lipid based nanoparticles for drug delivery with matrix solution type compared with other types as represented in (Figure 4, Figure 5, Figure 6 and Figure 7) shows prolonged drug release which means that this type of systems has high loading capacity of the various chemotherapy active compounds which means this systems type offers a novel way to locally deliver the drugs to the targeted place. 
Table 1: Chemotherapeutic Agent examples and its application.

\begin{tabular}{|c|c|c|c|c|c|c|}
\hline $\begin{array}{l}\text { Chemotherapeutic } \\
\text { Agent }\end{array}$ & \multicolumn{2}{|c|}{$\begin{array}{l}\text { Anti- } \\
\text { cancer } \\
\text { Diffusion } \\
\text { coefficient }\end{array}$} & Application & $\begin{array}{l}\text { Partition } \\
\text { coefficients }\end{array}$ & Dose/Days & Reference \\
\hline Doxorubicin & $\begin{array}{l}6.7 \\
\mathrm{~cm}^{2} / \mathrm{s}\end{array}$ & $x$ & $\begin{array}{l}\text { Breast } \\
\text { cancer }\end{array}$ & 3.91 & $\begin{array}{l}60 \text { to } 75 \\
\mathrm{mg} / \mathrm{m}^{2} \\
\text { repeated } \\
\text { every } 21 \\
\text { days }\end{array}$ & $\begin{array}{l}\text { Alves } \\
\text { al.(2017; } \\
\text { Prescribers } \\
\text { Digital } \\
\text { Reference(2018; } \\
\text { Weinberg et } \\
\text { al.(2007) }\end{array}$ \\
\hline Taxanes & $\begin{array}{l}2.56 \\
\mathrm{~cm}^{2} / \mathrm{s}\end{array}$ & $x$ & $\begin{array}{l}\text { Ovarian } \\
\text { cancer }\end{array}$ & 40.03 & $\begin{array}{l}60-100 \\
\mathrm{mg} / \mathrm{m} 2 \\
\text { repeated } \\
\text { every } 21 \\
\text { days }\end{array}$ & $\begin{array}{l}\text { Markl } \\
\text { al.(2017) }\end{array}$ \\
\hline Cisplatin & $\begin{array}{l}2.1 \\
\mathrm{~cm}^{2} / \mathrm{s}\end{array}$ & $x$ & $\begin{array}{l}\text { Bladder } \\
\text { cancer }\end{array}$ & 0.0865 & $\begin{array}{l}50 \text { to } 70 \\
\mathrm{mg} / \mathrm{m} 2 \\
\text { repeated } \\
\text { every } 28 \\
\text { days }\end{array}$ & $\begin{array}{lr}\text { Panczyk et } & \text { et } \\
\text { al.(2013; Suresh } \\
\text { Gyan Vihar Vin } \\
\text { University(2013) }\end{array}$ \\
\hline Doxil & $\begin{array}{l}3.72 \\
\mathrm{~cm}^{2} / \mathrm{s}\end{array}$ & $x$ & $\begin{array}{l}\text { Cell } \\
\text { Lymphoma } \\
\text { cancer }\end{array}$ & 1.34 & $\begin{array}{l}20 \text { to } 40 \\
\mathrm{mg} / \mathrm{m} 2 \\
\text { repeated } \\
\text { every } 28 \\
\text { days }\end{array}$ & $\begin{array}{l}\text { Toley } \\
\text { al.(2013) }\end{array}$ \\
\hline
\end{tabular}

Table 2: Base parameters values for used in doxorubicin drug and delivery devices for simulation (Dose $60 \mathrm{mg} / \mathrm{m}^{2}$ in 21 days).

\begin{tabular}{llll}
\hline \multicolumn{3}{l}{ Doxorubicin Drug and Delivery Devices Parameters } \\
\hline Formulation & $\begin{array}{l}\text { Diffusion } \\
\text { Coefficient } \\
\left.\mathbf{c m}^{2} / \mathbf{s}\right)\end{array}$ & $\begin{array}{l}\text { Radius } \\
\mathbf{n m}\end{array}$ & $\begin{array}{l}\text { Maximum } \\
\text { Release Rate }\end{array}$ \\
F1 & 6.7 & 9 & 89.65 \\
F2 & 6.7 & 12.6 & 80 \\
F3 & 6.7 & 26 & 62 \\
F4 & 6.7 & 29.5 & 60 \\
F5 & 6.7 & 32.5 & 58.5 \\
\hline
\end{tabular}

Table 3: Base parameters values for used in Taxotere drug and delivery devices for simulation (Dose $60-100 \mathrm{mg} / \mathrm{m}^{2}$ in 21 days).

\begin{tabular}{llll}
\hline \multicolumn{3}{l}{ Taxotere Drug and Delivery Devices Parameters } \\
\hline Formulation & $\begin{array}{l}\text { Diffusion } \\
\text { Coefficient } \\
\left.\mathbf{c m}^{2} / \mathbf{x}\right)\end{array}$ & $\begin{array}{l}\text { Radius } \\
\mathbf{n m}\end{array}$ & $\begin{array}{l}\text { Maximum } \\
\text { Release Rate }\end{array}$ \\
$\underline{\mathbf{F 1}}$ & $\underline{2.56}$ & $\underline{9}$ & $\underline{65}$ \\
$\underline{\mathbf{F 2}}$ & $\underline{2.56}$ & $\underline{12.6}$ & $\underline{57}$ \\
$\underline{\mathbf{F 3}}$ & $\underline{2.56}$ & $\underline{26}$ & $\underline{42.50}$ \\
\hline
\end{tabular}

Table 4: Base parameters values for used in cisplatin drug and delivery devices for simulation (Dose $50-70 \mathrm{mg} / \mathrm{m}^{2}$ in 28 days).

\begin{tabular}{llll}
\hline \multicolumn{3}{l}{ Cisplatin Drug and Delivery Devices Parameters } \\
\hline Formulation & $\begin{array}{l}\text { Diffusion } \\
\text { Coefficient } \\
\left.\mathbf{c m}^{2} / \mathbf{x}\right)\end{array}$ & $\begin{array}{l}\text { Radius } \\
\mathbf{n m}\end{array}$ & $\begin{array}{l}\text { Maximum } \\
\text { Release Rate }\end{array}$ \\
$\underline{\mathbf{F 1}}$ & $\underline{2.1}$ & $\underline{9}$ & $\underline{67}$ \\
$\underline{\mathbf{F 2}}$ & $\underline{2.1}$ & $\underline{12.6}$ & $\underline{59.50}$ \\
$\underline{\mathbf{F 3}}$ & $\underline{2.1}$ & $\underline{26}$ & $\underline{44}$ \\
\hline
\end{tabular}

Table 5: Base parameters values for used in Doxil drug and delivery devices for simulation (Dose $20-40 \mathrm{mg} / \mathrm{m}^{2}$ in 28 days).

\begin{tabular}{llll}
\hline \multicolumn{4}{l}{ Doxil Drug and Delivery Devices Parameters } \\
\hline Formulation & $\begin{array}{l}\text { Diffusion } \\
\text { Coefficient } \\
\left.\mathbf{c m}^{2} / \mathbf{s}\right)\end{array}$ & $\begin{array}{l}\text { Radius } \\
\mathbf{n m}\end{array}$ & $\begin{array}{l}\text { Maximum } \\
\text { Release Rate }\end{array}$ \\
$\underline{\mathbf{F 1}}$ & $\underline{3.72}$ & $\underline{\mathbf{5 2 . 5}}$ & $\underline{41.88}$ \\
$\underline{\mathbf{F 2}}$ & $\underline{3.72}$ & $\underline{60.5}$ & $\underline{39.5}$ \\
$\mathbf{F 3}$ & 3.72 & 70 & 37 \\
$\mathbf{F 4}$ & 3.72 & 83.2 & 34.1 \\
$\mathbf{F 5}$ & 3.72 & 90.5 & 33 \\
\hline
\end{tabular}




\section{International Journal of Engineering Applied Sciences and Technology, 2020 \\ Vol. 4, Issue 10, ISSN No. 2455-2143, Pages 277-286 \\ Published Online February 2020 in IJEAST (http://www.ijeast.com)}

In this study we compared different matrix solution spherical lipid nanoparticles delivery system loaded with various chemotherapy agent drugs such as (Doxorubicin, Taxanes, Cisplatin and Doxil) as listed in (Table 1) and the diffusion was simulated using (Eq.1) with difference particle radius which was ranging from 10 to $100 \mathrm{~nm}$ as listed in (Table 1 and 3),

In table 4 and 5 we found that as illustrate in (Figure 8, Figure 9, Figure 10 and Figure 11) the release rate amount over time is affected inversely by particle size, whereas the spherical geometric radius increases the release rate decreases and in the case of doxorubicin drug the amount of required dose is in the range $\left(60\right.$ to $\left.75 \mathrm{mg} / \mathrm{m}^{2}\right)$ at 21 days, as listed in (Table 2) the values of radius 26 and 29.5 $\mathrm{nm}$ are suitable to give the required amount when the diffusion coefficient $\mathrm{D}$ is $\mathrm{cm} 2 / \mathrm{s}$ as shown in (Figure 8), for Taxanes drug the amount of required dose is in the range (60 to $100 \mathrm{mg} / \mathrm{m} 2)$ at 21 days, as listed in table 3 , the values of radius $9 \mathrm{~nm}$ is suitable to give the required amount when the diffusion coefficient $\mathrm{D}$ is $\mathrm{cm} 2 / \mathrm{s}$ as shown in (Figure 9), also for Cisplatin drug the amount of required dose is in the range (50 to $70 \mathrm{mg} / \mathrm{m} 2$ ) at 28 days, as listed in table 4 , the values of radius 9 and 12.6 $\mathrm{nm}$ are suitable to give the required amount when the diffusion coefficient D is $\mathrm{cm} 2 / \mathrm{s}$ as shown in (Figure 10), finally in the case of Doxil the amount of required dose is in the range (20 to $40 \mathrm{mg} / \mathrm{m} 2$ at 28 days, as listed in (

Table 5) all the values of radius are suitable to give the required amount when the diffusion coefficient $\mathrm{D}$ is $\mathrm{cm} 2 / \mathrm{s}$ as shown in (Figure 11).

In other words, the active ingredient release from the nanoparticle its clear in that it is very sensitive to this particle size Eltayeb et al.(2015). Markedly, many factors are able to govern the drug release from the nanoparticles inside the body after administration and those factors include drug solubility, drug initial concentration, matrix and drug diffusion coefficients, particle size and partition coefficient Yahia et al.(2018) and from the data set that were reported in the Eltayeb et al.(2016) experiment where this study worked with both homogenous matrix and coreshell nanoparticles with tenable size we deduced that also the polymer to drug ratio is effected on the particle delivery system tape as well as the drug release as 1:1 or $4: 4 \mathrm{w} \%$, the system tends to be a matrix particle. on the same way when the polymer to drug ratio is $1: 3,1: 4$ or $2: 4$ $\mathrm{w} \%$, the system tends to be core-shell particle.

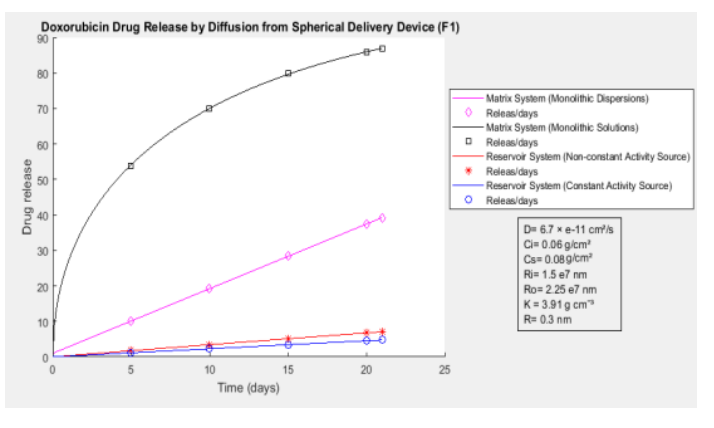

Figure 4: Doxorubicin Drug Release by Diffusion from Spherical Matrix Systems and Reservoir Systems Delivery Devices.

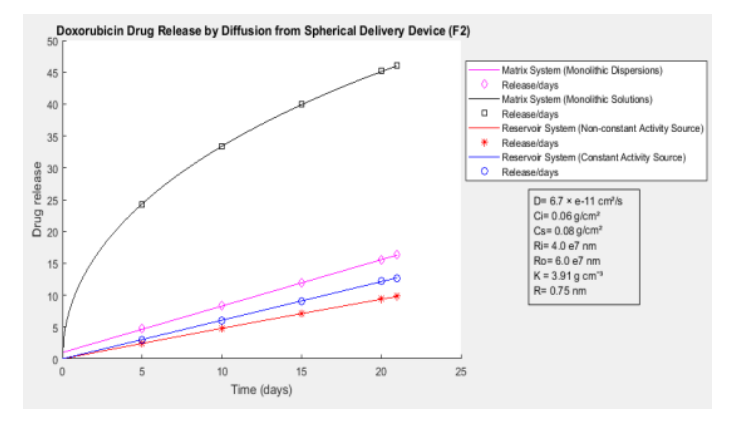

Figure 5: Doxorubicin Drug Release by Diffusion from Spherical Matrix Systems and Reservoir Systems Delivery Devices.

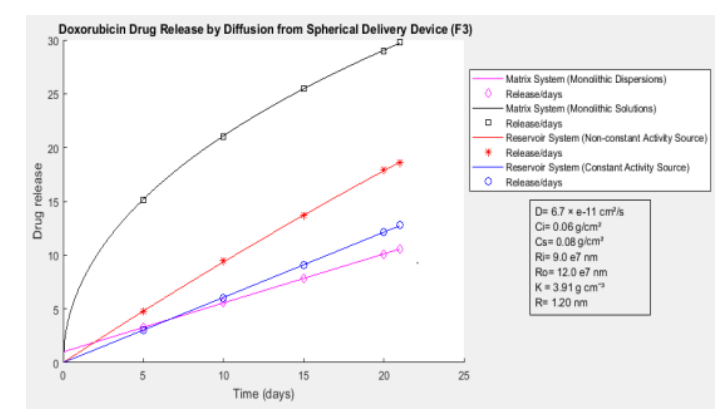

Figure 6: Doxorubicin Drug Release by Diffusion from Spherical Matrix Systems and Reservoir Systems Delivery Devices.

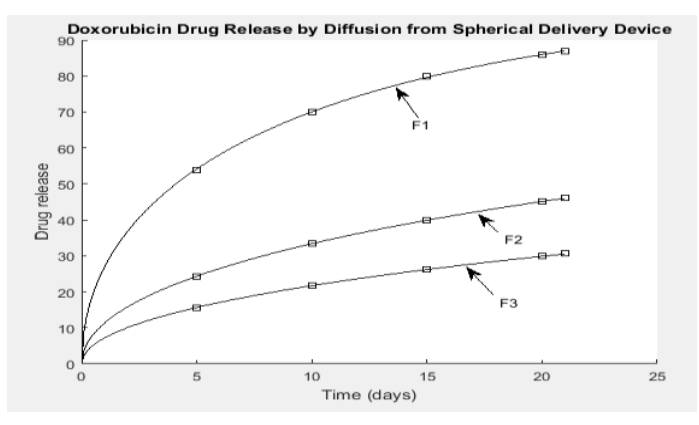

Figure 7: Doxorubicin Drug Release by Diffusion from Spherical Monolithic Solutions Delivery Devices with Different Radius $\mathrm{F} 1=0.3 \mathrm{~nm}, \mathrm{~F} 2=0.75 \mathrm{~nm}$ and $\mathrm{F} 3=1.20 \mathrm{~nm}$. 


\section{International Journal of Engineering Applied Sciences and Technology, 2020 \\ Vol. 4, Issue 10, ISSN No. 2455-2143, Pages 277-286 \\ Published Online February 2020 in IJEAST (http://www.ijeast.com)}

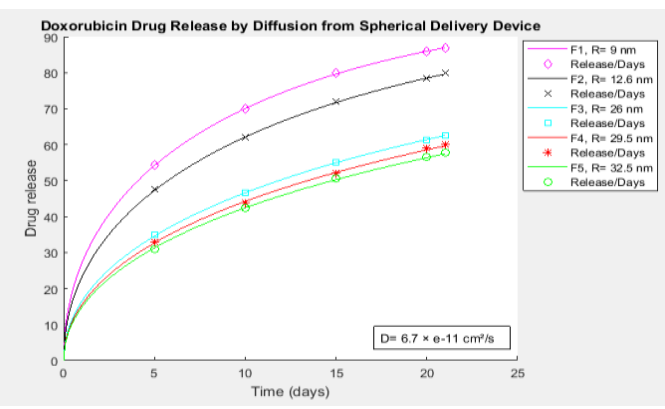

Figure 8: Doxorubicin Drug Release by Diffusion from Spherical Monolithic Solutions Delivery Devices with Different Radius.

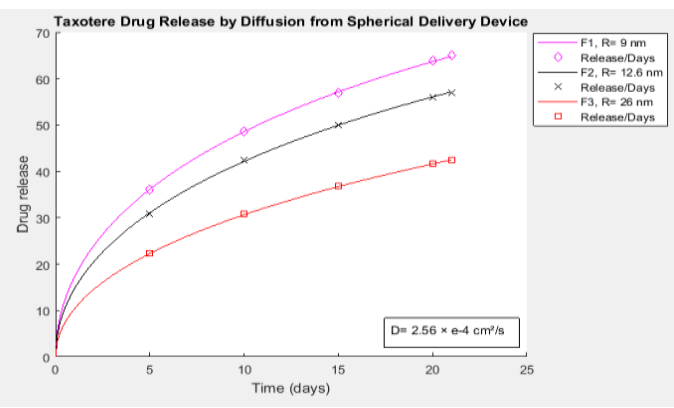

Figure 9: Taxotere Drug Release by Diffusion from Spherical Monolithic Solutions Delivery Devices with Different Radius.

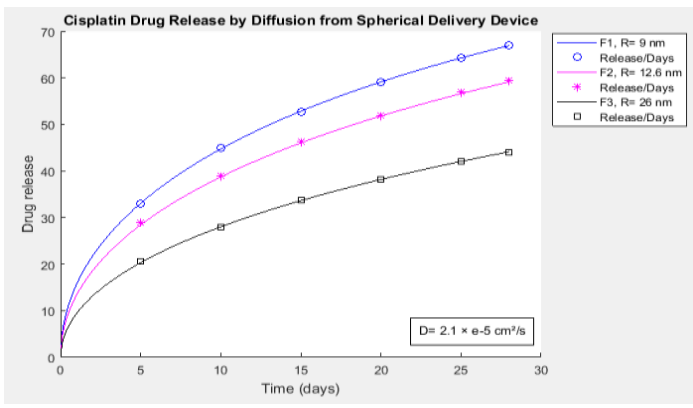

Figure 10: Cisplatin Drug Release by Diffusion from Spherical Monolithic Solutions Delivery Devices with Different Radius.

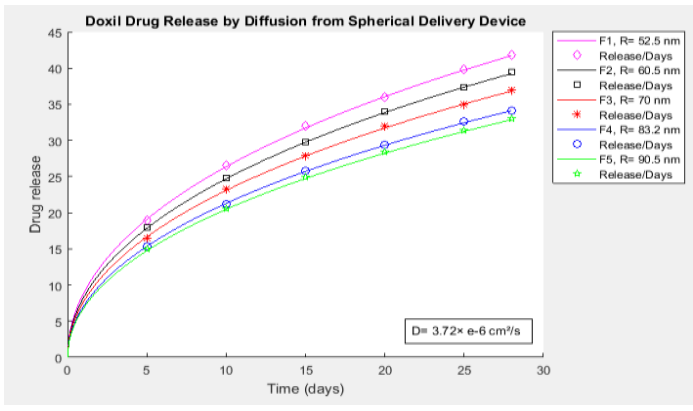

Figure 11: Doxil Drug Release by Diffusion from Spherical Monolithic Solutions Delivery Devices with Different Radius.

\section{CONCLUSION}

The solid lipid nanoparticles occupy the top list of nanoparticles in the treatment of cancer, although they have a few side effects, they are expected to have prominence in the future in the field of cancer treatment for human beings. The release of drug molecules from both matrix systems or reservoir devices can be predicted using mathematical equations to describe drug release kinetics with varying properties of drugencapsulated substances, altering the chemical and physical properties of the drug and analyze their effects on the launch process where the release rate can be simulated easily by using computer software. In addition, these programs can be used to better understand the proliferation mechanism that controls drug release from advanced delivery systems. Significantly, it is important to know both the ratio or the concentration of the initial drug loaded in the device and the solubility of the drug which facilitate the differentiation between the matrix and reservoir delivery devices system types. As well as know the radius and size of nanoparticles which is a major factor that affecting the drug release and from the computational model we found that the drug release could be controlled by varying the radius values for the formulations.

\section{REFERENCE}

1. Alves, Ana Catarina, Magarkar, Aniket, Horta, Miguel, Lima, Jose LFC, Bunker, Alex, Nunes, Cláudia, \& Reis, Salette. (2017). Influence of doxorubicin on model cell membrane properties: insights from in vitro and in silico studies. Scientific reports, 7(1), (pp. 6343).

2. Bhatia, Saurabh. (2016). Nanoparticles types, classification, characterization, fabrication methods and drug delivery applications Natural polymer drug delivery systems (pp. 33-93): Springer.

3. da Silva Luz, Glécia Virgolino, Barros, Kleber Vânio Gomes, de Araújo, Fábio Vladimir Calixto, da Silva, Gabriela Barbosa, da Silva, Pedro Augusto Ferreira, Condori, Roxana Claudia Iquize, \& Mattos, Lourdes. (2016). Nanorobotics in drug delivery systems for treatment of cancer: a review. J Mat Sci Eng A, 6, (pp. 167-180).

4. Eltayeb, Megdi, Stride, Eleanor, \& Edirisinghe, Mohan. (2013). Electrosprayed core-shell polymer-lipid nanoparticles for active component delivery. Nanotechnology, 24(46), (pp. 465604).

5. Eltayeb, Megdi, Stride, Eleanor, \& Edirisinghe, Mohan. (2015). Preparation, characterization and release kinetics of ethylcellulose nanoparticles encapsulating ethylvanillin as a model functional component. Journal of Functional Foods, 14, (pp. 726-735). 


\section{International Journal of Engineering Applied Sciences and Technology, 2020 \\ Vol. 4, Issue 10, ISSN No. 2455-2143, Pages 277-286 \\ Published Online February 2020 in IJEAST (http://www.ijeast.com)}

6. Eltayeb, Megdi, Stride, Eleanor, Edirisinghe, Mohan, \& Harker, Anthony. (2016). Electrosprayed nanoparticle delivery system for controlled release. Materials Science and Engineering: $C$, 66, (pp. 138-146).

7. Fan, LT, \& Singh, SK. (1989). Controlled release: a quantitative treatmentSpringer. Berlin, New York, (pp.

8. Freiberg, Stephan, \& Zhu, XX. (2004). Polymer microspheres for controlled drug release. International journal of pharmaceutics, 282(1-2), (pp. 1-18).

9. Friberg, Lena E, Hassan, Saadia B, Lindhagen, Elin, Larsson, Rolf, \& Karlsson, Mats O. (2005). Pharmacokinetic-pharmacodynamic modelling of the schedule-dependent effect of the anti-cancer agent $\mathrm{CHS}$ 828 in a rat hollow fibre model. European journal of pharmaceutical sciences, 25(1), (pp. 163-173).

10. Gharpure, Kshipra M, Wu, Sherry Y, Li, Chun, LopezBerestein, Gabriel, \& Sood, Anil K. (2015). Nanotechnology: future of oncotherapy. Clinical Cancer Research, 21(14), (pp. 3121-3130).

11. Heller, J. (1987). Controlled drug release from monolithic systems Ophthalmic Drug Delivery (pp. 179189): Springer.

12. Jabir, Nasimudeen R, Tabrez, Shams, Ashraf, Ghulam Md, Shakil, Shazi, Damanhouri, Ghazi A, \& Kamal, Mohammad A. (2012). Nanotechnology-based approaches in anticancer research. International journal of nanomedicine, 7, (pp. 4391).

13. Jain, KK. (2005). Nanotechnology-based drug delivery for cancer. Technology in cancer research \& treatment, 4(4), (pp. 407-416).

14. Langer, Robert. (1990). New methods of drug delivery. Science, 249(4976), (pp. 1527-1533).

15. Markl, Daniel, Yassin, Samy, Wilson, D Ian, Goodwin, Daniel J, Anderson, Andrew, \& Zeitler, J Axel. (2017). Mathematical modelling of liquid transport in swelling pharmaceutical immediate release tablets. International journal of pharmaceutics, 526(1-2), (pp. 1-10).

16. Muhamad12, Ida Idayu, Selvakumaran, Suguna, \& Lazim, Nurul Asmak Md. (2014). Designing polymeric nanoparticles for targeted drug delivery system. Nanomed, 287, (pp. 287).

17. Naseri, Neda, Valizadeh, Hadi, \& Zakeri-Milani, Parvin. (2015). Solid lipid nanoparticles and nanostructured lipid carriers: structure, preparation and application. Advanced pharmaceutical bulletin, 5(3), (pp. 305).

18. Negut, Irina, Grumezescu, Valentina, Dorcioman, Gabriela, \& Socol, Gabriel. (2017). Microscale Drug Delivery Systems: Current Perspectives and Novel Approaches Nano-and Microscale Drug Delivery Systems (pp. 1-15): Elsevier.

19. Panczyk, Tomasz, Jagusiak, Anna, Pastorin, Giorgia, Ang, Wee Han, \& Narkiewicz-Michalek, Jolanta. (2013). Molecular dynamics study of cisplatin release from carbon nanotubes capped by magnetic nanoparticles. The
Journal of Physical Chemistry C, 117(33), (pp. 1732717336).

20. Prescribers Digital Reference. (2018). doxorubicin hydrochloride - Drug Summary. from https://www.pdr.net/drug-summary/DoxorubicinHydrochloride-doxorubicin-hydrochloride-1876

21. Ruckmani, K, Sivakumar, M, \& Ganeshkumar, PA. (2006). Methotrexate loaded solid lipid nanoparticles (SLN) for effective treatment of carcinoma. Journal of nanoscience and nanotechnology, 6(9-10), (pp. 29912995).

22. Sahoo, Sanjeeb K, \& Labhasetwar, Vinod. (2003). Nanotech approaches to drug delivery and imaging. Drug discovery today, 8(24), (pp. 1112-1120).

23. Shenoy, VS, Vijay, IK, \& Murthy, RSR. (2005). Tumour targeting: biological factors and formulation advances in injectable lipid nanoparticles. Journal of pharmacy and pharmacology, 57(4), (pp. 411-421).

24. Siepmann, F, Muschert, S, Flament, MP, Leterme, P, Gayot, A, \& Siepmann, J. (2006). Controlled drug release from Gelucire-based matrix pellets: experiment and theory. International journal of pharmaceutics, 317(2), (pp. 136-143).

25. Siepmann, Juergen, Siegel, Ronald A, \& Siepmann, Florence. (2012). Diffusion controlled drug delivery systems Fundamentals and applications of controlled release drug delivery (pp. 127-152): Springer.

26. Siepmann, Juergen, \& Siepmann, Florence. (2012). Modeling of diffusion controlled drug delivery. Journal of Controlled Release, 161(2), (pp. 351-362).

27. Singh, Rajesh, \& Lillard Jr, James W. (2009). Nanoparticle-based targeted drug delivery. Experimental and molecular pathology, 86(3), (pp. 215-223).

28. Stylios, George K, Giannoudis, Peter V, \& Wan, T. (2005). Applications of nanotechnologies in medical practice. Injury, 36(4), (pp. S6-S13).

29. Suresh Gyan Vihar University. (2013). Observations, Result and Discussion chapter: 4

30. Thassu Deepak, Michel Deleers, \& Yashwant Vishnupant Pathak. (2007). Nanoparticulate Drug Delivery Systems (1 ed. Vol. 166): Informa Healthcare.

31. Toley, Bhushan J, Lovatt, Zachary G Tropeano, Harrington, Josephine L, \& Forbes, Neil S. (2013). Microfluidic technique to measure intratumoral transport and calculate drug efficacy shows that binding is essential for doxorubicin and release hampers Doxil. Integrative Biology, 5(9), (pp. 1184-1196).

32. Torchilin, V. (2011). Fundamentals and Applications of Controlled Release Drug Delivery: Springer US Boston, MA:.

33. Vizirianakis, Ioannis S. (2014). Handbook of Personalized Medicine: Advances in Nanotechnology, Drug Delivery, and Therapy: CRC Press.

34. Weinberg, Brent D, Patel, Ravi B, Exner, Agata A, Saidel, Gerald M, \& Gao, Jinming. (2007). Modeling 
doxorubicin transport to improve intratumoral drug delivery to RF ablated tumors. Journal of Controlled Release, 124(1-2), (pp. 11-19).

35. Werner, Benjamin, Scott, Jacob G, Sottoriva, Andrea, Anderson, Alexander RA, Traulsen, Arne, \& Altrock, Philipp M. (2016). The cancer stem cell fraction in hierarchically organized tumors can be estimated using mathematical modeling and patient-specific treatment trajectories. Cancer research, (pp. canres. 2069.2015).

36. Wyss Institute for Biologically Inspired Engineering at Harvard. (2014). Delivering chemo drugs on cue: Ultrasound and self-healing hydrogels deliver drugs noninvasively at right place, right time.

37. Yahia, I, Atif, R, Ahmed, L, Salah Eldeen, T, Omara, A, \& Eltayeb, M. (2018). Modelling of Polymeric Nanoparticles Mechanisms of Controlled Drug Release Delivery Systems. International Journal of Nano and Biomaterials (Submitted), (pp.

38. Yang, Wan-Wan, \& Pierstorff, Erik. (2012). Reservoirbased polymer drug delivery systems. Journal of laboratory automation, 17(1), (pp. 50-58).

39. Yousaf, AS, \& Ali, Salamat. (2008). Why Nanoscience and Nanotechnology? What is there for us? J. of Faculty of Eng. \& Technol, 5, (pp. 11-20).

40. Zhang, Ying, Chan, Hon Fai, \& Leong, Kam W. (2013). Advanced materials and processing for drug delivery: the past and the future. Advanced drug delivery reviews, 65(1), (pp. 104-120). 